\title{
DOSSIE
}

\section{$O$ que pode a cultura material enquanto fonte para o estudo da história afro-brasileira e africana nas escolas? Por um ensino de História pluriepistêmico}

\author{
What can material culture as a source for the study \\ of afro-brazilian and african history in schools? \\ For a pluriepistemic history teaching
}

\author{
Clarissa Adjuto Ulhoa \\ Doutora em História pela UFG \\ Professora do Curso de História da Universidade Federal de Jataí \\ clarissau@gmail.com
}

\begin{abstract}
RESUMO: O presente texto tem o intuito de demonstrar que a cultura material, ao ser abarcada como fonte para o ensino da história e da cultura afro-brasileira e africana, tem o potencial de contribuir para práticas pautadas em pluriepistemologias. Para tanto, argumentamos sobre a necessidade de debater o papel das fontes diretas no ensino de História, bem como expomos possibilidades advindas do estudo da fonte material, em diálogo com a chamada arqueologia da diáspora. Dessa maneira, discutimos como as estratégias materiais colocadas em prática pelos africanos e por seus descendentes nos permitem perceber uma parcela de seu complexo repertório de conhecimentos.

PALAVRAS-CHAVE: Pluriepistemologias. Cultura material. História afro-brasileira e africana.
\end{abstract}

\begin{abstract}
This text aims to demonstrate that material culture, when used as a source for the teaching of Afro-Brazilian and African history and culture, has the potential to contribute to practices based on pluriepistemologies. Therefore, we argue about the need to debate the role of direct sources in the teaching of history, as well as exposing possibilities arising from the study of the material source, in dialogue with the so-called diaspora archeology. In this way, we discuss how the material strategies put into practice by Africans and their descendants allow us to realize a part of their complex repertoire of knowledge.
\end{abstract}

KEYWORDS: Pluriepistemologies. Material culture. Afro-brazilian and african history.

\section{Introdução}

Em pesquisa realizada em sete escolas públicas estaduais situadas na cidade de Goiânia, Goiás, foi possível constatar que a maioria dos estudantes dos nonos anos do 
Revista do Corpo Discente do Programa de Pós-Graduação em História da UnB

EM TEMPO DE HISTóRIAS | Brasília-DF | n. 36 | p. 328-347 | jan./jun. 2020.

ISSN 2316-1191

ensino fundamental e dos terceiros anos do ensino médio percebem a cultura material atribuída aos africanos e a seus descendentes baseados em perspectivas reducionistas, estereotipadas e, portanto, apartadas da complexidade do universo material afrobrasileiro e africano (ULHOA, 2018). Quando solicitados a representarem exemplares da cultura material que acreditam estar associados às sociedades africanas, a maior parte dos estudantes recorreu ao berimbau, ao tambor e ao colar ${ }^{1}$. Já no caso das materialidades que acreditam estar relacionados às comunidades afro-brasileiras, a maior parte dos estudantes também recorreu ao berimbau e ao tambor, mas agora somado ao chicote $^{2}$ (ULHOA, 2018). Diante desses dados, por um lado notamos que ainda se encontra fortemente presente entre aqueles estudantes perspectivas fundadas no eurocentrismo e no colonialismo, ao passo que, por outro lado, suspeitamos que a cultura material afro-brasileira e africana possivelmente não tem sido abarcada em toda sua amplitude enquanto fonte para o ensino de História.

No entanto, argumentamos que o estudo da cultura material em sala de aula se mostra fundamental não somente por ser reveladora de uma das importantes dimensões da experiência humana, mas sobretudo porque a consideramos uma fonte de análise privilegiada para um ensino da história e da cultura afro-brasileira e africana que contemple pluriepistemologias. Esse entendimento se sustenta, a princípio, na característica ubiquidade da cultura material, posto que permeia a totalidade das atividades humanas (MENESES, 1983), bem como na máxima de que as materialidades, distintamente do que ocorre no caso de outros registros históricos, se encontram associadas a ricos e pobres, livres e escravizados, homens e mulheres, adultos e crianças (SOUZA, 2011). Sendo assim, consideramos que a análise das fontes materiais permite que acessemos parte do repertório de saberes dos africanos e de seus descendentes, sobretudo no que concerne ao período escravista brasileiro, o que se apresenta como uma alternativa possível caso não queiramos nos limitar às fontes elaboradas a partir de perspectivas tributárias do eurocentrismo e da colonialidade. Essa proposta, se assumida como recurso metodológico para o ensino de História, pode contribuir para que os estudantes notem que o domínio material da cultura relacionado aos africanos e a seus descendentes está para muito além do berimbau.

Por meio do presente texto, pretendemos apresentar alguns apontamentos no sentido de responder à pergunta: o que pode a cultura material enquanto fonte para o estudo da história afro-brasileira e africana nas escolas em bases pluriepistêmicas? Primeiramente, apresentamos os debates construídos por estudiosos que pensam as epistemologias para além dos cânones das ciências modernas, compreendendo, por exemplo, que conhecimentos sistemáticos também são elaborados no âmbito dos movimentos negros. Diante disso, se discute a necessidade de pensarmos estratégias

\footnotetext{
${ }^{1}$ Dos 978 questionários totais respondidos, em termos percentuais os resultados mostraram as seguintes representações: berimbau, $25 \%$; tambor, $17 \%$; colar, $14 \%$; lança, $10 \%$; vaso, $6 \%$; turbante, $6 \%$; jarro, $6 \%$; arco e flecha, $6 \%$; cabana, $3 \%$; chocalho, $2 \%$; pandeiro, $1 \%$; pirâmide, $1 \%$; enxada, $1 \%$; chicote, $1 \%$; roupas, $1 \%$.

2 Dos 978 questionários totais respondidos, em termos percentuais os resultados mostraram as seguintes representações: berimbau, 35\%; tambor, $13 \%$; chicote, $6 \%$; turbante, $7 \%$; vaso, $5 \%$; feijoada, $5 \%$; colar, $4 \%$; arco e flecha, $4 \%$; capoeira, $3 \%$; enxada, $3 \%$; pandeiro, $3 \%$; panela, $2 \%$; lança, $2 \%$; bola de futebol, $2 \%$; algemas, $1 \%$; chocalho, $1 \%$; navio negreiro, $1 \%$.
} 
Revista do Corpo Discente do Programa de Pós-Graduação em História da UnB

Em TEMPO DE HISTÓRIAS | Brasília-DF | n. 36 | p. 328-347 | jan./jun. 2020.

ISSN 2316-1191

para que os currículos das instituições de ensino contemplem pluriepistemologias. Em seguida, abordamos aspectos referentes ao papel das fontes históricas no ensino escolar, sobretudo no sentido de argumentar sobre a necessidade de incluir as fontes diretas ao abordarmos temas da história e da cultura afro-brasileira e africana, o que anuncia as possibilidades advindas da análise da cultura material em sala de aula. Finalmente, preocupados em estabelecer diálogos com os arqueólogos, apresentamos exemplos de como as materialidades podem revelar os saberes que compõem o repertório dos africanos e de seus descendentes, com recorte no contexto escravista. Dessa maneira, esperamos contribuir para os recentes debates que se dedicam, no campo do ensino de História, a pensar estratégias que descolonizem o conhecimento, sobretudo no sentido de colaborar para os requisitos estabelecidos na Lei 10639/2003.

\section{Epistemologia e pluriepistemologia}

Muito embora os domínios coloniais perpetrados pelas metrópoles europeias tenham se encerrado após as duradouras lutas pela independência política nos continentes americano, africano e asiático, uma série de continuidades desses mesmos domínios insistem em se colocar permanentemente presentes, inclusive no que se refere às esferas epistêmicas e ontológicas. Tais continuidades podem ser chamadas de colonialidades, que se desdobram em pelo menos três dimensões: a colonialidade do poder, a colonialidade do saber e a colonialidade do ser. Em linhas gerais, a colonialidade do poder se estrutura com base nas assimetrias de raça, de gênero e de trabalho, destinadas ao controle por parte dos europeus sobre outros povos do mundo (QUIJANO, 1998). Já a colonialidade do saber parte do entendimento de que apenas a ciência moderna ocidental pode construir conhecimento legítimo, enquanto a colonialidade do ser desconsidera o direito do não europeu de existir (MALDONADOTORRES, 2007). Reconhecer que não existe apenas uma epistemologia legítima, assim como não existe somente uma pedagogia possível, consiste em um ponto de partida essencial no sentido de se contrapor às mencionadas colonialidades.

De acordo com Walter Mignolo (2003), a palavra epistemologia, em seu sentido platônico, se constituiu com base no termo 'episteme', o qual se refere a um dado conhecimento construído de modo sistemático, pautado em uma série de regras e, portanto, mais próximo daquilo que mais tarde se compreenderia enquanto ciência. Em contraponto à denominada 'episteme' se encontra a chamada 'doxa', que se refere a um conhecimento elaborado a partir do bom senso, mas sem necessariamente se pautar em regras ou em sistemáticas. Segundo Boaventura de Sousa Santos (2019), a epistemologia inicialmente se restringia à crítica ao conhecimento construído pela ciência, mas, atualmente, seu sentido se expandiu, de modo que também se dedica à análise dos processos que antecedem e que permitem considerar válido um dado conhecimento. Para os autores citados, entretanto, as perspectivas relativas à epistemologia que correntemente circulam nas culturas acadêmicas se encontram perpassadas pelas colonialidades e, por isso, corroboram para que somente uma epistemologia eurocentrada se imprima enquanto tal. Diante disso, ambos constroem críticas que apontam para a necessidade de pensarmos em termos pluriepistêmicos. 
Revista do Corpo Discente do Programa de Pós-Graduação em História da UnB

Em TEMPO DE HISTÓRIAS | Brasília-DF | n. 36 | p. 328-347 | jan./jun. 2020.

ISSN 2316-1191

Mignolo (2003) elabora sua análise por meio do resgate do termo 'gnose', que assume o papel de denominar o conhecimento como um todo, incluindo, assim, não apenas a 'episteme', como também a 'doxa'. Baseado no mencionado termo, constrói o conceito de gnose liminar, que se refere ao conhecimento concebido a partir das margens externas do sistema mundial-colonial moderno, com base, portanto, na perspectiva de sujeitos subalternos. Em outras palavras, a gnose liminar pode ser entendida enquanto a racionalidade subalterna na luta por revelar a potência e a criatividade de seus saberes, os quais inclusive atuam como pilares sobre os quais a modernidade e a racionalidade moderna foram gestadas. Em sentido semelhante, o autor propõe o conceito de gnosiologia liminar, que se refere ao pensamento crítico diante dos conhecimentos elaborados tanto nas margens internas quanto nas margens externas do sistema mundial-colonial moderno. Dessa maneira, tem como intuito construir um aparato conceitual que propicie o deslocamento das formas hegemônicas de conhecimento postas pela epistemologia e pela ciência moderna, tendo como ponto de partida as perspectivas de epistemologias/gnosiologias outras.

É importante ressaltar que, ao dispor no centro de sua análise a ideia de 'gnose', o autor parte dos debates primeiramente suscitados por Valentim Mudimbe (MIGNOLO, 2003). Diante da demanda de construir um panorama da filosofia africana, Mudimbe precisou lidar com um problema revelador das colonialidades: por um lado, estava sendo chamado a pensar a partir da filosofia, uma das disciplinas modernas tributária do colonialismo; por outro lado, precisava abarcar os indisciplinados conhecimentos tradicionais africanos, sem os quais seus escritos se apresentariam profundamente incompletos, mesmo que esses mesmos conhecimentos tenham sido historicamente considerados subalternos por aquela filosofia (MIGNOLO, 2003). Para tanto, recorreu à 'gnose' no intuito de congregar uma série de conhecimentos que a filosofia e a epistemologia tinham persistentemente descartado, entendendo gnose no sentido de "procurar saber, indagar, método de conhecimento, investigação e, mesmo, conhecimento de alguém" (MUDIMBE apud MIGNOLO, 2003, p. 33). Ele esclarece, ainda, que 'gnose' não corresponde à 'doxa', assim como não equivale à 'episteme', posto que, em sua perspectiva, um não pode ser tomado como o antônimo do outro:

\footnotetext{
Mudimbe tem o cuidado de especificar que gnose não equivale nem a doxa nem a episteme. Episteme, Mudimbe esclarece, significa tanto ciência quanto configuração intelectual sobre o conhecimento sistemático, ao passo que a doxa é o tipo de conhecimento de que a própria conceitualização de episteme necessita como seu exterior: a episteme não é apenas a conceitualização do conhecimento, mas é também a condição de possibilidade da doxa; não é o seu antônimo (MIGNOLO, 2003, p. 33).
}

Santos (2019), distintamente dos autores supracitados, parece não considerar necessária a propositura de um termo inteiramente alternativo à epistemologia, conforme se pretende a proposta da gnose e da gnosiologia. Ele se concentra naquilo que chama de "ocupar a epistemologia", com o intuito de ressignificar o seu papel "enquanto instrumento de interrupção das políticas dominantes e dos conhecimentos que as sustentam" (SANTOS, 2019, p. 18). Mesmo assim, acrescenta ao termo um elemento que irrompe com seu sentido inicial, se referindo aos saberes gestados pelo cosmopolitismo subalterno como epistemologias do sul: conhecimentos construídos e legitimados no 
Revista do Corpo Discente do Programa de Pós-Graduação em História da UnB

Em TEMPO DE HISTÓRIAS | Brasília-DF | n. 36 | p. 328-347 | jan./jun. 2020.

ISSN 2316-1191

âmbito das lutas e das experiências de grupos sociais que têm sido oprimidos pelo capitalismo, pelo colonialismo e pelo patriarcado. Sendo assim, não se trata de um sul estritamente geográfico, mas de suis epistemológicos, embora frequentemente se sobreponham, principalmente em se tratando dos países sujeitos ao colonialismo histórico. Nesse mesmo sentido, as chamadas epistemologias do norte, não se restringem ao norte geográfico, pois também se estabelecem nas "pequenas Europas epistemológicas" próprias do sul imperial (SANTOS, 2019, p. 17). Tais epistemologias do norte se apoiam numa suposta supremacia das ciências modernas.

No entanto, as epistemologias do sul não devem ser encaradas como meras imagens refletidas das epistemologias do norte, o que seria, de acordo com o autor, apenas mais uma maneira de se realinhar à estrutura dualista binária própria da lógica ocidental. Nesse sentido, as epistemologias do sul não pretendem substituir as epistemologias do norte, mas sim superar a dicotomia que tem prevalecido entre ambas no decorrer do tempo. Para tanto, será necessário, na perspectiva do autor, construir um pensamento com base naquilo que chama de ecologia de saberes, no intuito de reconhecer que saberes fundamentalmente distintos entre si coexistem, bem como no sentido de perceber como tais saberes se assemelham, se divergem, se complementam, se contrapõem. No âmbito de uma ecologia de saberes, para além dos conhecimentos construídos com base nos pressupostos das ciências modernas, se encontram os conhecimentos elaborados nos processos de luta social e política. Tendo como protagonistas aqueles que insurgem contra o racismo, a xenofobia, o machismo e a homofobia, as epistemologias do sul, frequentemente gestadas na prática coletiva, revelam não apenas saberes ignorados pelo norte, como também abalam as lógicas que determinam quem pode conhecer e quem pode ser conhecido:

[...] as epistemologias do sul desafiam as epistemologias dominantes em dois níveis diferentes. Por um lado, consideram crucial a tarefa de identificar e discutir a validade de conhecimentos e de modos de saber não reconhecidos como tal pelas epistemologias dominantes. Concentram-se, dessa forma, em conhecimentos 'inexistentes', assim considerados pelo fato de não serem produzidos de acordo com metodologias aceitáveis, ou mesmo inteligíveis, ou porque são produzidos por sujeitos 'ausentes', sujeitos concebidos como incapazes de produzir conhecimento válido devido à sua impreparação ou mesmo à sua condição não plenamente humana [...]. Por outro lado, os sujeitos que são [...] trazidos à presença, são muitas vezes sujeitos coletivos, o que altera completamente a questão da autoria do conhecimento e, portanto, a questão da relação entre o sujeito que conhece e o objeto do conhecimento. (SANTOS, 2019, p. 19).

Nilma Lino Gomes (2017), em diálogo com a perspectiva das epistemologias do sul, analisa os saberes que têm sido construídos no âmbito do Movimento Negro Brasileiro, o qual emergiu de maneira mais orgânica nos anos 1970. De acordo com a autora, os conhecimentos elaborados pelos partícipes desse movimento social podem ser entendidos como saberes emancipatórios. Esses saberes revelam não apenas uma maneira de compreender o mundo, como também uma racionalidade, a qual se encontra permeada pela experiência da raça, em uma sociedade que, como a brasileira, se estrutura em pilares racializados desde que se conformou enquanto tal. Portanto, os saberes emancipatórios de negros e negras têm atuado ao longo da história no sentido 
Revista do Corpo Discente do Programa de Pós-Graduação em História da UnB

Em TEMPO DE HISTÓRIAS | Brasília-DF | n. 36 | p. 328-347 | jan./jun. 2020.

ISSN 2316-1191

de intervir na sociedade, na cultura e na política do país, processo que não ocorre em termos meramente intuitivos, mas, ao contrário, se transcorre de forma intencional e direcionada. Sendo assim, a autora demonstra que a experiência da raça consiste em parte dos processos regulatórios colocados em prática pelos africanos e por seus descendentes no tempo, não somente no sentido de transgredir, libertar e emancipar, como também na busca por produzir e reproduzir sua existência.

Para a autora, podem ser apontados pelos menos três saberes que têm sido elaborados pelos negros e pelas negras no país, os quais se constroem de forma imbricada, mas que, como recurso analítico e didático, cabem ser apresentados separadamente: os saberes identitários, os saberes políticos e os saberes estéticocorpóreos. De acordo com a autora, os saberes identitários se referem ao modo como o Movimento Negro Brasileiro atua para que debates relativos a quem é negro e a quem é branco extrapolem os limites da militância e cheguem à sociedade brasileira como um todo, sobretudo em torno da questão das políticas de ações afirmativas. Nesse mesmo sentido, temas relacionados à identidade negra passam a ocupar, mesmo que lentamente, redutos dos quais estiveram por muito tempo excluídos: as redes sociais, a literatura, as artes, a pesquisa, o poder público. Desse modo, a sociedade brasileira segue "compreendendo que ser negro e negra e afirmar-se enquanto tal é um posicionamento político e identitário que desconforta as elites e os poderes instituídos" (GOMES, 2017, p. 70-71), o que ocorre a despeito das estratégias racistas que tentam silenciar as denúncias que emergem desses saberes identitários.

No que tange aos saberes políticos, a autora destaca o papel do Movimento Negro Brasileiro no sentido de pressionar os poderes governamentais e as áreas do conhecimento a mudarem sua atitude e sua perspectiva diante da raça e do racismo no país. No caso dos poderes governamentais, esse movimento conquistou políticas públicas estabelecidas por lei, tais como o Estatuto da Igualdade Racial (2010), as Cotas Sociorraciais no Ensino Superior (2012) e as Cotas nos Concursos Públicos Federais (2014). Já no âmbito das áreas do conhecimento, no que se refere à pesquisa e ao ensino, a autora ressalta o papel de intelectuais negros e negras que têm formado coletivos como a Associação de Pesquisadores Negros, responsável pelo bianual evento denominado Congresso Brasileiro de Pesquisadores e Pesquisadoras Negros, além dos diversos Núcleos de Estudos Afro-Brasileiros, que contribuem para a produção de um número crescente de pesquisas. Dessa maneira, se antes diversos profissionais e intelectuais se esquivavam dos debates sobre raça e racismo, essa postura passa a ser mais questionada, segundo a autora. Ela também destaca o papel exercido pelo Movimento de Mulheres Negras no que se refere aos saberes políticos.

Já os saberes estético-corpóreos passam pelo modo como negras e negros, bem como a sociedade brasileira em geral, têm reeducado sua relação com o corpo e com a estética, principalmente devido às políticas de ações afirmativas. Essa mudança pode ser percebida sobretudo entre os jovens que, distintamente das gerações anteriores, se afirmam por meio de seu corpo e de sua estética, ao mesmo tempo em que ocupam outros lugares sociais. Para a autora, os saberes estético-corpóreos, por serem os mais perceptíveis da relação dos negros e das negras com o mundo, podem, contraditoriamente, ser aqueles mais usados para impor sua não existência, devido ao 
Revista do Corpo Discente do Programa de Pós-Graduação em História da UnB

Em TEMPO DE HISTÓRIAS | Brasília-DF | n. 36 | p. 328-347 | jan./jun. 2020.

ISSN 2316-1191

racismo e ao mito da democracia racial. Dessa maneira, as características que os distinguem acabam subsumidas em nome de um híbrido considerado mais aceitável socialmente, tal como expressa o uso comum da alcunha de "moreno". Sendo assim, a autora considera que os saberes estético-corpóreos se postam para além do sentido de estética da arte, pois se referem "[...] à estética como forma de sentir o mundo, como corporeidade, como forma de viver o corpo no mundo" (GOMES, 2019, p. 79). Diante disso, ela destaca, novamente, o papel das mulheres negras, que, ao criticarem modelos que definem seus corpos como exóticos e eróticos, bem como modelos que estabelecem o que é belo, têm encampado movimentos de orgulho da estética negra.

José Jorge de Carvalho (2019), ao escrever sobre a necessidade de os currículos universitários contemplarem epistemologias que, tal como as mencionadas acima escapam dos modelos colonialista e eurocêntrico, escolhe usar uma categoria que parece abranger também a relação com as epistemologias das ciências modernas no âmbito das instituições de educação: pluriepistemologia. De acordo com o autor, as políticas públicas, sobretudo as de cotas para ingresso de negros e indígenas no ensino superior, são extremamente importantes, pois permitiram a presença desses estudantes nas universidades brasileiras. No entanto, as cotas de acesso ao ensino superior precisam estar necessariamente acompanhadas daquilo que chama de cotas epistêmicas, no sentido de também garantir que mestres dos saberes tradicionais atuem como professores universitários em disciplinas regulares. Dessa maneira, os estudantes não teriam acesso apenas aos conhecimentos eurocêntricos modernos, mas também aos conhecimentos das comunidades tradicionais. Para o autor, se restritas apenas aos discentes, as cotas podem passar a ardilosa mensagem de que os estudantes negros e indígenas chegam à universidade para finalmente aprenderem com os brancos os saberes que importam. Portanto, para se contrapor a essa lógica perversa, será necessário oferecer um ensino comprometido com a pluriepistemologia.

\section{Pluriepistemologias e ensino de História: a questão das fontes}

Mignolo (2008), ao explicar os mecanismos que permeiam a colonialidade do saber, ressalta que as ciências sociais modernas desde o princípio desconsideraram os tratados de intelectuais que construíram seus pensamentos desde as margens do sistema mundial-colonial moderno. Dentre os tratados sistematicamente ignorados, se encontram o Nueva Crónica y Bien Gobierno (1615), escrito por Wama Poma de Ayala (1534-1615), um representante do vice-reinado peruano de ascendência inca, e o Thoughts and Sentiments on the Evil Slavery (1787), elaborado por Quobna Otobbah Cugoano (1757-1791), um pensador ganense e escravizado liberto. De acordo com o autor, ambos os escritos se contrapõem ao colonialismo e, por causa dos inegáveis contributos que fornecem aos debates sobre a política moderna, dentre outros assuntos, deveriam ter sido colocados no mesmo patamar que autores como Nicolau Maquiavel (1469-1527), Thomas Hobbes (1588-1679) e John Locke (1639-1704). Sendo assim, o autor considera que a continuidade do apagamento daqueles pensadores, assim como de outros como eles, pode resultar da perda de parte importante da genealogia do pensamento que desde o século XV questiona a lógica da modernidade. 
Revista do Corpo Discente do Programa de Pós-Graduação em História da UnB Em TEMPO DE HISTÓRIAS | Brasília-DF | n. 36 | p. 328-347 | jan./jun. 2020.

ISSN 2316-1191

Diante disso, ao situar esse debate no campo do ensino de História, nos parece essencial perceber que uma prática docente comprometida com a pluriepistemologia passa necessariamente pelo ato de repensar a escolha das fontes a serem debatidas em sala de aula. No intento de incentivar os nossos estudantes a compreenderem, por exemplo, as ideias dos pensadores dos séculos XV e XVI, não bastará propor análises dos escritos de Hobbes e Locke, será necessário contemplar também Ayala e Cugoano, inclusive no sentido de entender de que maneira os autores divergem ou convergem em suas leituras da realidade. E em se tratando, particularmente, do ensino da história africana e afro-brasileira, será igualmente fundamental propor em sala de aula o estudo de fontes que permitam aos estudantes se aproximarem das perspectivas dos africanos e de seus descendentes no tempo, sem, portanto, se limitar às fontes elaboradas a partir da narrativa do branco, colonizador, escravista. Sendo assim, consideramos especialmente importante retomarmos o debate sobre o papel desempenhado pelas fontes históricas na sala de aula, pois entendemos que assumem centralidade para um ensino de História que se pretende pluriepistêmico.

José de Assunção Barros (2012), muito embora considere que o conceito de fonte histórica se constituiu quase como uma obviedade nos dias atuais, dedica algumas linhas para expor seu entendimento. Para ele, fonte histórica consiste em tudo aquilo que, ao ser elaborado pelos seres humanos ou ao apresentar sinais de sua interferência, pode nos permitir acesso à uma compreensão sobre o passado. Percorrido um longo percurso de debates entre os historiadores, atualmente, segundo o autor, quase não existem limites quanto às possibilidades de quaisquer coisas serem transformadas em fontes históricas. Desde a escrita, a materialidade e a oralidade, até o corpo, a gestualidade e a paisagem, para pontuar apenas alguns exemplos. Enquanto recurso analítico, o autor também distingue dois tipos de fontes históricas, as indiretas e as diretas, o que se relaciona "[...] à questão da possibilidade de que ocorram intermediações no processo informativo ou de produção de uma fonte histórica" (BARROS, 2012, p. 134). Sendo assim, considera como fontes indiretas aquelas em que o anunciador transmite um determinado aspecto sobre a realidade passando por um intermediário ou mais. Já as fontes diretas consistem naquelas que se encontram "[...] em uma cadeia documental, testemunhal ou informativa, colocando-se, por exemplo, entre o historiador e um primeiro documento ou testemunho, anterior a todos" (BARROS, 2012, p. 134). Mas ressalta a complexidade dessas categorias:

Nenhuma fonte, destarte, é direta ou indireta de maneira absoluta. Qualquer classificação nesse sentido depende do objeto que tenhamos em vista [...]. Se tomarmos a obra História do historiador grego Heródoto (484-425a.C.), essa poderá ser considerada uma fonte indireta no que se refere aos relatos referentes às gerações que o precederam, mas pode ser considerada fonte direta no que se refere aos relatos que lhe foram contemporâneos, ou presenciáveis pelo próprio Heródoto. Por outro lado, mesmo nos relatos que se referem a períodos anteriores à época de Heródoto, os seus textos podem ser considerados fonte direta, desde que o nosso objeto de estudo seja não propriamente aquele conjunto de acontecimentos, mas a visão que deles tinham Heródoto [...]. Essa questão é complexa, e relaciona-se ao fato de que as várias fontes ou documentos narrativos podem ser tratados de um lado como "testemunhos de uma época ou situação", e de outro lado como "discursos de uma época". De todo modo, veremos que a questão é ainda mais complexa, já que as intermediações não se dão apenas 
Revista do Corpo Discente do Programa de Pós-Graduação em História da UnB

Em TEMPO DE HISTÓRIAS | Brasília-DF | n. 36 | p. 328-347 | jan./jun. 2020.

ISSN 2316-1191

diacronicamente (entre épocas distintas), mas, também, sincronicamente (no mesmo tempo) (BARROS, 2012, p. 134-135).

Circe Maria Bittencourt (2011), assim como outros pesquisadores do ensino de História, considera fundamental a análise de documentos históricos de tipos diversos em sala de aula, tomando como referência, claro, o seu papel essencial no âmbito da pesquisa histórica. No entanto, a autora ressalta que o estudo documental, ao ser proposto enquanto estratégia metodológica para se ensinar e se aprender história, não deve ser reivindicado com o intento de formar "pequenos historiadores", pois os pesquisadores profissionais atuam imbuídos de outro tipo de compromisso perante o conhecimento histórico. Em sala de aula, entendemos que o incentivo ao estudo das fontes se pauta na importância de os estudantes se aperceberem dos parâmetros teóricos e metodológicos em que se baseiam os historiadores ao construírem suas análises, além da possibilidade de se aparatarem para construir uma leitura crítica do conteúdo apresentado na disciplina. Para a autora, as fontes podem também ser aplicadas como maneira de ilustrar uma ideia expressa pelos professores ou pelos materiais didáticos, assim como podem ser usadas enquanto recursos introdutórios de um tema. Sendo assim, a autora ressalta que cabe aos professores estabelecerem critérios que embasem a escolha dessas fontes, atentos à necessidade de pensar o contexto histórico em que foram elaboradas, bem como em lembrar que consistem em registros do passado a serem interpretados e não um retrato do passado em si.

Carlos Moore Wedderburn (2005), ao debater o papel das fontes bibliográficas no ensino da história africana no Brasil, ressalta que parte delas se encontra permeada por uma série de preconceitos a respeito dos africanos, alimentados por uma duradoura perspectiva nociva sobre o continente e suas sociedades. Nesse mesmo sentido, explica que até os anos 1960 estava em curso um inegável monopólio por parte dos africanistas europeus, americanos e árabes na escrita da história das sociedades africanas, quase sempre imbuídos das lógicas essencialista e raciológica. Diante disso, o autor destaca a importância de os historiadores contemplarem o conhecimento elaborado pelos pesquisadores africanos, inclusive em suas atividades de ensino, pois, além de se contraporem aos danosos estereótipos, têm condição de apresentar uma perspectiva "a partir de dentro", por meio "[...] das mentalidades, cosmogonias, línguas e estruturas que moldaram aquelas sociedades ao longo da mais extensa história do planeta" (WEDDERBURN, 2005, p. 158). Em outras palavras, ele reivindica que o ensino da história africana se paute em pluriepistemologias, o que não será possível se as fontes adotadas se limitarem aos escritos dos africanistas.

Mas, no que se refere às fontes para o ensino da história e da cultura afrobrasileira e africana, uma importante questão se apresenta aos historiadores interessados em identificarem os saberes que os africanos e seus descendentes construíram e expressaram ao longo do tempo. Para acessarem tais conhecimentos, o compromisso dos pesquisadores em contemplarem fontes construídas a partir de linguagens, formatos e suportes diversos ultrapassa o recomendável para se tornar uma escolha metodológica realmente imprescindível. Na hipótese de os historiadores se limitarem aos documentos escritos, por exemplo, será possível notar que enquanto existe uma quantidade relevante de fontes indiretas disponíveis, inseridas nos mais diversos 
Revista do Corpo Discente do Programa de Pós-Graduação em História da UnB Em TEMPO DE HISTÓRIAS | Brasília-DF | n. 36 | p. 328-347 | jan./jun. 2020.

ISSN 2316-1191

períodos da história do país, o mesmo não ocorre no caso das fontes diretas. É preciso considerar que as colonialidades têm permanentemente contribuído não apenas para se estabelecer quem pode e quem não pode escrever, como também para selecionar de quem são os registros que devem ou não permanecer. Essa realidade pode ser percebida no caso dos estudos dedicados aos africanos e seus descendentes no período escravista brasileiro. Por um lado, existe um número expressivo de fontes escritas indiretas que falam sobre os escravizados, a exemplo dos relatos de cronistas europeus. Mas, por outro lado, existem poucas fontes escritas diretas que, ao serem elaboradas por aqueles sujeitos, mostram indícios de suas experiências desde dentro.

[...] na busca das fontes da escravidão, os pesquisadores tiveram que lidar com uma série de dificuldades, decorrentes não só da escassez de documentos sobre o tema da vida escrava, mas também, principalmente, daquelas causadas por uma incompatibilidade intrínseca entre as fontes oficiais e a história dos despossuídos ou dos dominados que se procurava resgatar. Em linhas gerais, foi preciso reconstituir a vida social e cultural das populações de africanos e afrodescendentes a partir da leitura de documentos comprometidos com a visão de mundo das classes dominantes [...]. Foi necessário também contornar a frieza de informações despersonalizadas ou puramente quantitativas, filtrar os testemunhos, ler nas entrelinhas e abstrair, no máximo do possível, os preconceitos, as visões preestabelecidas, as situações de constrangimentos, nas quais réus, escravos e forros se colocavam diante de juízes, policiais e escrivães para serem julgados. Nos anais da história da escravidão brasileira e das populações de afrodescendentes, foram raros ou raríssimos os depoimentos diretos deixados por esses setores sociais (WISSENBACH, 2002, p. 104).

Maria Cristina Cortez Wissenbach (2002), ao mencionar algumas das poucas fontes escritas diretas relacionadas ao período escravista, cita um tratado elaborado no final do século XVIII por escravizados rebelados do Engenho Santana, situado em Ilhéus. De acordo com a autora, o documento concentra uma série de exigências comunicadas pelos escravizados ao proprietário do engenho caso quisesse que retornassem ao trabalho, ao mesmo tempo em que demonstra "a capacidade dos escravos em reinterpretar a escravidão em seus próprios termos [...]" (WISSENBACH, 2002, p. 105). Ela também ressalta os processos judiciários que, em determinados casos, conservam em sua literalidade o relato direto de escravizados indiciados, bem como carregam em anexo cartas, preces e listas construídas a punho por esses sujeitos. É o que pode ser observado, segundo a autora, em um dos autos criminais da comarca de São Paulo que, datado de 1868 a 1872, contém em seu anexo cartas escritas pelo escravizado Claro Antônio dos Santos, a pedido da africana Theodora Dias da Cunha, as quais se tornaram indícios do processo instaurado pelo cônego Fidélis Alves Sigmaringa de Moraes. Consideramos interessante, ainda, mencionar o exemplo do documento de denúncia que a escravizada Esperança Garcia encaminhou ao presidente da província de São José do Piauí no ano de 1770, no qual está escrito:

Eu sou uma escrava de V.S ${ }^{a}$. administração de Capitão Antônio Vieira de Couto, casada. Desde que o Capitão lá foi administrar, que me tirou da Fazenda dos Algodões, onde vivia com meu marido, para ser cozinheira de sua casa, onde nela passo tão mal. A primeira é que há grandes trovoadas de pancadas em um filho, nem sendo uma criança que lhe faz extrair sangue pela boca; em mim não posso explicar que sou um colchão de pancadas, tanto que caí uma vez sobrado abaixo, peada, por misericórdia de Deus escapei. A segunda estou eu e mais minhas 
Revista do Corpo Discente do Programa de Pós-Graduação em História da UnB

Em TEMPO DE HISTÓRIAS | Brasília-DF | n. 36 | p. 328-347 | jan./jun. 2020.

ISSN 2316-1191

parceiras por confessar a três anos. E uma criança minha e duas mais por

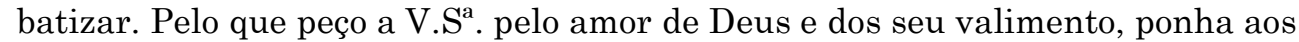
olhos em mim, ordenando ao Procurador que mande para a fazenda onde ele me

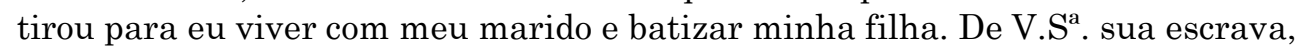
Esperança Garcia. (ESPERANÇA Garcia , 2020)

Em sala de aula, se tomamos como ponto de partida que as estratégias construídas na luta cotidiana revelam os saberes de que detinham os africanos e seus descendentes no tempo, a análise dessa fonte escrita direta pode contribuir para que os estudantes percebam uma série de conhecimentos revelados pelas palavras de Esperança Garcia. Em primeiro lugar, a autora demonstra que domina os saberes necessários para se expressar por meio da forma escrita e, em segundo lugar, mostra que conhece os trâmites administrativos indispensáveis para se encaminhar um documento de teor reivindicatório. Esse documento também revela a capacidade estratégico-argumentativa de Esperança Garcia, que, sabendo da importância atribuída aos costumes católicos por parte das elites da época, se preocupa em construir alguma proximidade com seus interlocutores ao concluir o texto explicando que quer providenciar o batismo de sua filha, por exemplo. Merece destaque, ainda, o trecho em que a autora se refere a outras mulheres, provavelmente escravizadas como ela, enquanto suas parceiras, o que fornece indícios do senso de comunidade compartilhado entre os africanos e seus descendentes durante o período escravista.

Portanto, por meio da análise dessa única fonte direta, os estudantes têm a oportunidade de acessar dados que podem contribuir para o questionamento de uma série de reducionismos e estereótipos, os quais, alimentados pelo eurocentrismo e pela colonialidade, insistentemente correlacionam os sujeitos escravizados às ideias de rusticidade, ignorância, incapacidade e indolência. Sendo assim, em se tratando de estratégias metodológicas para um ensino da história e da cultura afro-brasileira e africana pautado na perspectiva das pluriepistemologias, insistimos na importância de os professores garantirem que as fontes indiretas possam, de um lado, ser sempre contextualizadas e problematizadas e, de outro, possam ser interpeladas a partir do diálogo e do confronto com fontes diretas. Para tanto, consideramos imprescindível que os professores proponham o estudo não apenas das fontes escritas em sala de aula, as quais ainda nos parecem privilegiadas enquanto recursos para se ensinar e aprender História, mas também recorram às fontes orais, pictóricas, fotográficas, etc. Em nossa perspectiva, no entanto, um tipo particular de fonte, que acaba sendo um tanto quanto esquecida pelos historiadores, pode contribuir bastante para um ensino da história e da cultura afro-brasileira e africana pluriepistêmico: a cultura material.

Kátia Maria Abud e col. (2010) podem ser apontados como parte dos poucos historiadores que se propuseram a construir algum debate a respeito da cultura material enquanto fonte para se ensinar e se aprender História. De acordo com os autores, o estudo da cultura material permite que percebamos "[...] mudanças nas relações sociais das sucessivas gerações com esses mesmos artefatos" (ABUD e col., 2010 , p. 105). No intuito de ilustrar essa premissa, citam uma crônica de Mário Prata (2003), em que crianças se apercebem dos benefícios do uso das antigas máquinas de escrever, em detrimento dos computadores, o que exemplifica o modo como gerações distintas se apropriam da materialidade. Diante disso, os autores ressaltam a dimensão 
Revista do Corpo Discente do Programa de Pós-Graduação em História da UnB

Em TEMPO DE HISTÓRIAS | Brasília-DF | n. 36 | p. 328-347 | jan./jun. 2020.

ISSN 2316-1191

histórica da cultura material no cotidiano, o que, no aspecto metodológico, impõe aos historiadores o desvelamento dos usos dados às materialidades, das finalidades para as quais foram elaboradas, além de observar como foram concebidas em termos de materiais e técnicas. Para os autores, aos professores cabe um planejamento claro, preocupado em responder questões a respeito do modo como diferentes sociedades interagem com os artefatos ao longo da história, entendimento que os levam, inclusive, a sugerir atividades a serem aplicadas em sala. Ressaltam, ainda, o papel da análise da cultura material para que os estudantes compreendam sua realidade, bem como a necessidade de atribuir maior centralidade a essa fonte:

Esse procedimento privilegia a construção da consciência histórica nos alunos, de forma a torna-los agentes de seu próprio pensamento à medida que interpretam os artefatos que os cercam e/ou que lhes são apresentados diariamente nos sistemas midiáticos, não somente por seu aspecto utilitário, mas também pelo caráter ideológico embutido nesses objetos [...]. Assim, o estudo da cultura material no ensino de História sai da marginalização, à qual geralmente é destinada por seu pouco uso nos espaços escolares. De igual forma, deixa de ser utilizado apenas para ilustrar um momento histórico discutido ou referendar um documento escrito que, porventura, pode tê-lo citado - prática recorrente quando se trata do uso de artefatos para ensinar História, sobretudo nos livros didáticos (ABUD e col., 2010, p. 116).

Entretanto, conquanto consideremos relevante o debate apresentado pelos autores, acreditamos que os historiadores, em especial aqueles que pensam a partir do campo do ensino de História, precisam se preocupar em dialogar de maneira mais aprofundada com o conhecimento arqueológico, o qual tem se estruturado em torno do estudo da cultura material desde os oitocentos. Embora tenham recorrido aos escritos de alguns poucos arqueólogos para fundamentarem suas análises, sobretudo no que se refere aos aspectos teórico-conceituais, ainda assim não se dedicaram a apresentar quaisquer dados das pesquisas de campo que têm sido empreendidas pelos estudiosos dessa disciplina, nem mesmo no sentido de fornecerem alguns exemplos, o que consideramos um preocupante limitador. Por um lado, concordamos que a cultura material tem sido tradicionalmente esquecida enquanto fonte de ensino e de pesquisa por parte dos historiadores, mas, ao mesmo tempo, acreditamos que tal realidade apenas poderá ser mudada se levarmos para a sala de aula os resultados que têm sido apresentados nas diferentes subdisciplinas do campo arqueológico. Em se tratando particularmente do ensino da história e da cultura afro-brasileira e africana, será essencial estabelecer diálogos com a chamada arqueologia da diáspora.

\section{O que pode a cultura material?}

Tânia Andrade de Lima (2011) considera a cultura material como sendo “[...] qualquer segmento do meio físico modificado por comportamentos culturalmente determinados", além de ser "indissociável e constitutiva da condição humana desde o seu surgimento, onipresente no mundo [...]" (LIMA, 2011, p. 12-13). De acordo com a autora, muito embora os estudos sobre a cultura material ocorram no seio das ciências humanas em geral, são os arqueólogos os responsáveis por construírem e consolidarem um aparato teórico, metodológico e técnico destinado à análise do domínio material da 
Revista do Corpo Discente do Programa de Pós-Graduação em História da UnB EM TEMPO DE HISTóRIAS | Brasília-DF | n. 36 | p. 328-347 | jan./jun. 2020.

ISSN 2316-1191

cultura, concentrados, sobretudo, em um trio de aspectos da experiência social: forma, espaço e tempo. Na história do pensamento arqueológico, a cultura material se percebeu anunciada a partir de perspectivas teóricas diversas, cada uma das quais, segundo a autora, oferecendo importantes contributos para a disciplina. Na perspectiva pósprocessualista, da qual nos parece interessante partir, a cultura material consiste em um tipo de narrativa textual, que se estrutura, portanto, a partir de um sistema de signos. Sendo assim, “[...] os textos materiais devem ser lidos, sua sintaxe desvendada, estando implícito o fato de que as pessoas os leem diferentemente, de tal forma que a cultura material está aberta a múltiplas interpretações”, ponderando, além do mais, que "[...] é produzida não por um sistema, mas por indivíduos com escolhas ideologicamente determinadas" (LIMA, 2011, p. 19).

Lucas de Mendonça Marques (2015), ao debater os limites da perspectiva pósprocessualista, apresenta uma crítica à continuidade de uma série de dualidades, as quais sabemos que se constroem alimentadas pela lógica moderna. Ele ressalta, sobretudo, a ainda recorrente "[...] distinção ontológica entre pessoas e coisas, onde o poder para definir o mundo e imputar-lhe significado continuou sendo propriedade soberana do sujeito que experimenta o mundo" (MARQUES, 2015, p. 66). Enquanto uma alternativa possível, o autor aborda a necessidade de se construir conhecimento arqueológico a partir de uma atitude simétrica, o que passa, antes de mais nada, por eliminar os pressupostos que distinguem natureza e cultura, material e social, coisas e pessoas. Para tanto, será necessária uma nova postura metodológica, em que se parta da relação entre coisas e pessoas, sem privilegiar, portanto, a balança coisas-pessoas, conforme explica o autor. Sendo assim, "pessoas e coisas, nessa proposta, constituem-se mutuamente, formam coletivos de interação [...]" (MARQUES, 2015, p. 68). Em complementariedade, o autor entende que "[...] devemos partir do centro e, a partir da ação dos próprios coletivos, seguir as diversas ligações e negociações que realizam entre eles" (MARQUES, 2015, p. 69). Para ilustrar sua perspectiva, o autor apresenta o exemplo das ferramentarias dos orixás de candomblé, as quais não podem ser lidas a partir de uma lógica estanque e categórica que separe indivíduo, coisa e divindade:

Um [...] exemplo poderia ser formulado a partir das reflexões obtidas em minha própria pesquisa, sobre a ferramentaria-de-orixás na Bahia [...]: ao lidar, por exemplo, com a construção de uma ferramenta de Exu, é possível separar a priori o ferro do próprio orixá, ou do adepto, da comida recebida ou do próprio ferreiro? Em uma ontologia que não partilha dos mesmos dualismos modernos que compartilhamos, separar a priori uma coisa da outra é, no mínimo, impor uma visão de mundo nossa sobre outras pessoas e coisas (MARQUES, 2015, p. 68).

Em se tratando da mencionada ferramentaria dos orixás, se a tomarmos como fonte de análise, será necessário pontuar que tais exemplares da cultura material, inseridos que estão na cosmogonia dos candomblés, compõem especialmente os denominados assentamentos. Em linhas gerais, a cada um dos orixás se atribui um território específico no âmbito dos terreiros, nos quais são assentados os elementos simbólico-materiais que o constituem, ato prescindido por uma série de rituais. Cada um dos candomblecistas carrega consigo um orixá principal, considerado a divindade orientadora de sua existência, para a qual se estabelece um assentamento individual. De tempos em tempos, segundo as normas religiosas, àqueles elementos simbólico- 
Revista do Corpo Discente do Programa de Pós-Graduação em História da UnB

EM TEMPO DE HISTóRIAS | Brasília-DF | n. 36 | p. 328-347 | jan./jun. 2020.

ISSN 2316-1191

materiais, à ferramentaria que forma o assentamento, os adeptos oferecem alimento, sempre levando em conta as comidas da preferência de cada uma das divindades. Por isso, essa mesma ferramentaria não pode ser lida apenas em sua dimensão material pura e simples, pois, ao mesmo tempo em se apresenta enquanto coisa, consiste em uma divindade que orienta alguém: coisa-divindade-alguém, portanto. Diante desse exemplo, entendemos que a cultura material, se assumida enquanto um sistema de signos, bem como se pensada enquanto um imbricamento de coisas-pessoas/pessoas-coisas, tem o potencial de anunciar pluriepistemologias, sobretudo se tomada como fonte para o ensino da história e da cultura afro-brasileira e africana.

Luís Cláudio Pereira Symanski (2014) explica que os debates relativos à cultura material associada ao universo dos africanos e de seus descendentes se congregam no âmbito da chamada arqueologia da diáspora. De acordo com o autor, a pesquisa arqueológica que antecederia o estabelecimento dessa subdisciplina ocorreu nos Estados Unidos, nos anos 1940, mais precisamente no quintal de uma casa situada no interior do estado de Massachusetts, onde morou, entre os anos de 1815 e 1845, a liberta de nome Lucy Foster. No entanto, o estudo se limitou a descrever a cultura material encontrada, sem que os envolvidos se dedicassem, portanto, a uma análise acurada do material arqueológico. Foi somente no início da década de 1970 que, segundo o autor, passaram a ocorrer pesquisas realmente sistemáticas em sítios arqueológicos afroamericanos, sobretudo em senzalas dos estados da Flórida e da Geórgia. No Brasil, a arqueologia da diáspora passa a se consolidar no fim dos anos 1970, contando com grande influência de pesquisadores estadunidenses. Em um primeiro momento, os arqueólogos se dedicaram sobretudo ao estudo dos quilombos, principalmente aqueles situados em Minas Gerais e, na década de 1990, passaram a abarcar antigas senzalas, a princípio centradas no Rio de Janeiro. Nos últimos anos, os interesses da arqueologia da diáspora têm se expandido, incluindo, dentre outros tipos de sítios arqueológicos, os cemitérios de escravizados e os terreiros de candomblé.

Marcos André Torres de Souza (2013), um dos pesquisadores da arqueologia da diáspora, tem se dedicado a demonstrar como a análise da cultura material elaborada e apropriada pelos africanos e por seus descendentes, particularmente em contexto escravista, tem o potencial de revelar aquilo que denomina de estratégias materiais. De acordo com o autor, as formas de controle exercidas pelos senhores escravistas impactaram diretamente a existência dos indivíduos tornados escravos, motivo pelo qual aponta ser comum entre os historiadores o entendimento de que possuíam um universo material pobre e limitado. No entanto, o autor considera que, apesar da brutalidade própria do sistema escravista, os africanos e seus descendentes criaram maneiras ricas e diversas de se expressarem materialmente, realidade que somente poderá ser observada caso se ultrapasse os conceitos próprios da ótica eurocêntrica. Nas palavras do autor, "[...] estudos arqueológicos recentes têm demonstrado que esses indivíduos se engajaram ativamente no desenvolvimento de estratégias que lhes permitiram transpor, ao menos em parte, as limitações que lhes eram impostas [...]" (SOUZA, 2013, p. 12). Dentre as estratégias materiais apontadas se encontram ao menos um trio: estratégias para adquirir, estratégias para produzir e estratégias para reusar. 
Revista do Corpo Discente do Programa de Pós-Graduação em História da UnB

Em TEMPO DE HISTÓRIAS | Brasília-DF | n. 36 | p. 328-347 | jan./jun. 2020.

ISSN 2316-1191

Em se tratando das estratégias para adquirir exemplares da cultura material, o autor cita pesquisa empreendida no Engenho Água Fria, datado dos oitocentos e situado na Chapada dos Guimarães, Mato Grosso. Esse estudo apontou que 47,3\% da padronagem decorativa das louças encontradas nas senzalas não se repetiam na sede, o que sugere que os itens teriam sido adquiridos pelos próprios escravizados, provavelmente em mercados locais, e não necessariamente doados pelos donos do engenho (SYMANSKI apud SOUZA, 2013). Já no que se refere às estratégias para produzir, o autor cita pesquisa executada no Tapera do Pingador, quilombo igualmente situado na Chapada dos Guimarães. Esse estudo encontrou uma lixeira ao lado do alicerce do que teria sido uma casa, na qual coletaram fragmentos de recipientes cerâmicos com marcas que indicam que o mesmo fraturou durante o processo de queima, o que mostra que naquele local se elaborava recipientes cerâmicos próprios (SYMANSKI apud SOUZA, 2013). Enfim, no que tange às estratégias para reusar, o autor cita pesquisa feita no Engenho São Joaquim, datado de 1800 e situado em Pirenópolis, Goiás. Esse estudo recuperou na senzala parte de um garfo de metal com três dos seus dentes dobrados, o qual teria sido transformado para ser usado como perfurador [figura 01].

01

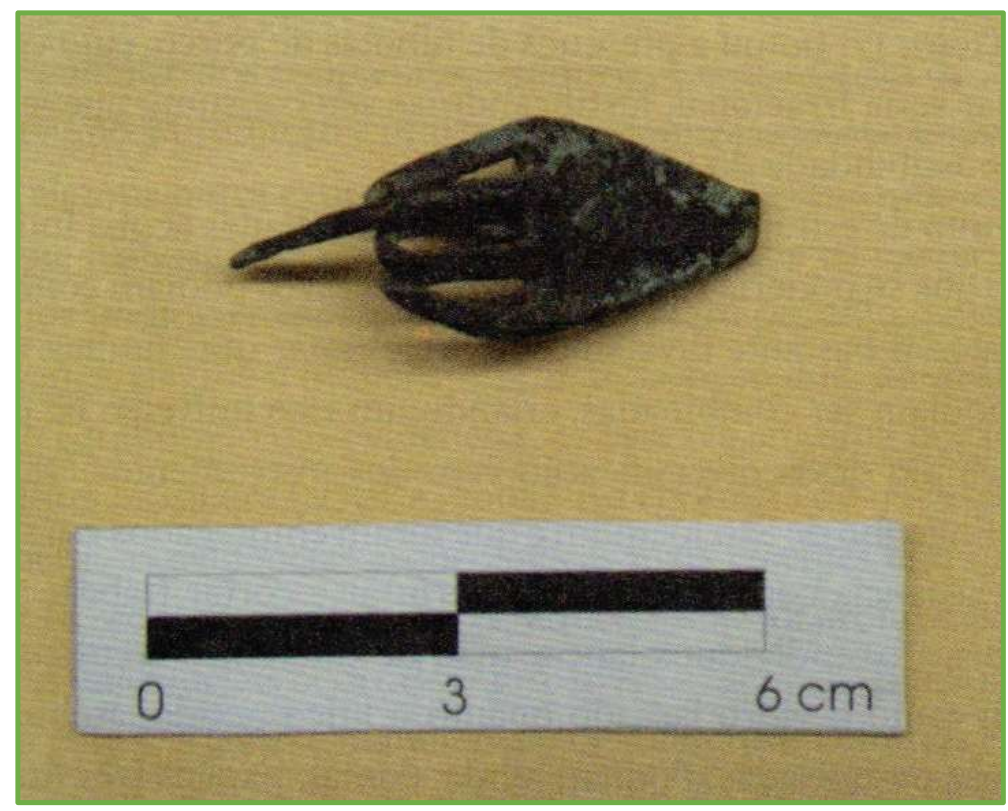

Fonte: SOUZA, 2013, p. 21.

Perante as estratégias elencadas, consideramos que, ao tomarmos a cultura material como fonte de análise, podemos acessar os conhecimentos que constituem o repertório dos africanos e de seus descendentes principalmente de duas maneiras distintas: com ênfase nos procedimentos de feitura e com ênfase nos processos de uso de uma determinada materialidade, muito embora saibamos que consistem em dimensões que se encontram imbricadas. No que concerne aos procedimentos de feitura, será necessário observar etapas tais como a triagem das matérias-primas, o emprego das técnicas construtivas e a escolha dos elementos decorativos, por exemplo. Dessa maneira, será possível observar os conhecimentos necessários para que alguém antecipe, manipule e elabore determinado exemplar da cultura material, a exemplo dos 
Revista do Corpo Discente do Programa de Pós-Graduação em História da UnB

EM TEMPO DE HISTóRIAS | Brasília-DF | n. 36 | p. 328-347 | jan./jun. 2020.

ISSN 2316-1191

mencionados recipientes cerâmicos, assim como são desenvolvidos conhecimentos à medida em que alguém delimita, testa e atesta procedimentos para que uma dada materialidade tenha sua funcionalidade mudada, a exemplo do citado talher de metal. No que se refere aos processos de uso, será necessário observar os conhecimentos relacionados ao preparo dos alimentos, os quais contribuem para a escolha do recipiente destinado ao consumo, por exemplo. Em todos os casos, ao mesmo tempo em que se operam aspectos técnicos, associados à materialidade dos gestos, se operam aspectos mentais, relacionados à imaterialidade do pensamento.

Para ilustrarmos os conhecimentos dos africanos e de seus descendentes que podem ser percebidos a partir da análise dos processos de feitura e de uso das materialidades, tomemos como parâmetro alguns dos artefatos resgatados nos sítios arqueológicos do Cais do Valongo [figura 02], localidade apontada como um dos mais frequentados portos de desembarque de africanos no Rio de Janeiro durante os oitocentos (LIMA e col., 2016). Em se tratando dos procedimentos de feitura, destacamos o anel que tem como matéria-prima uma fibra conhecida como piaçava. Convidado a conhecer o material arqueológico recuperado na pesquisa, o literato Wole Soyinka observou que anéis como aquele ainda são usados no oeste do continente africano como amuletos e, quando o disseram que aquela fibra em particular só podia ser encontrada no Brasil, o nigeriano de pronto rebateu: "eles improvisavam" (SOUZA, 2013, p.11). Esse acontecido contribui para que percebamos não apenas estratégias por meio das quais a matéria-prima se apresenta adaptada, mas principalmente os conhecimentos de que detinham sobre as plantas brasileiras. Já no que concerne aos processos de uso, destacamos as contas de colares e o brinco em meia lua, os quais, associados aos corpos de seus donos, comunicam e partem de conhecimentos sobre o mundo que estão intimamente relacionados ao pensamento cosmogônico africano.

02

\section{Objetos encontrados no Valongo}

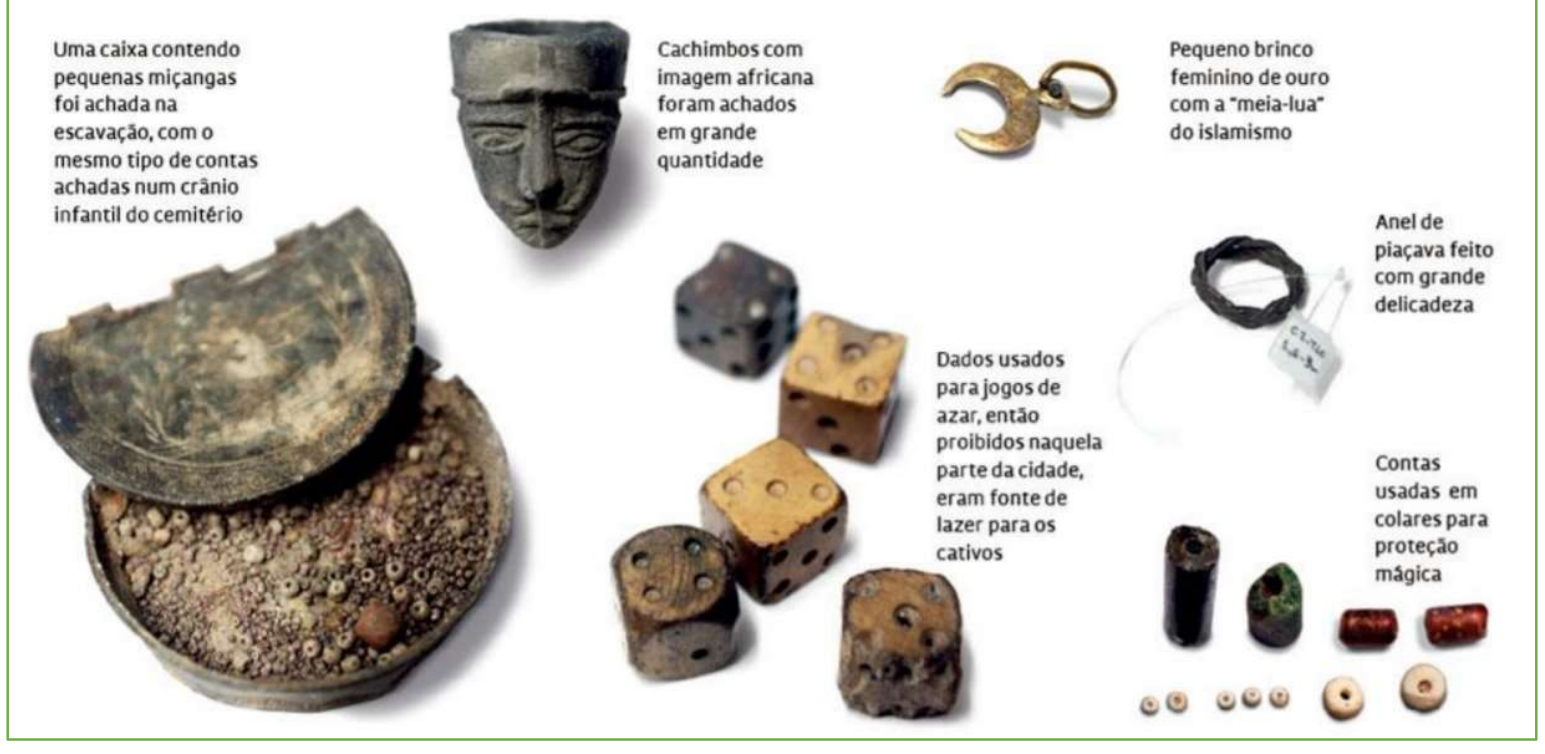

Fonte: IPHAN apud PAZ, 2019, p. 152. 
Revista do Corpo Discente do Programa de Pós-Graduação em História da UnB

Em TEMPO DE HISTÓRIAS | Brasília-DF | n. 36 | p. 328-347 | jan./jun. 2020.

ISSN 2316-1191

Finalmente, ressaltamos que o estudo da cultura material tem sobretudo o potencial de apresentar indícios dos saberes que foram (re)elaborados na diáspora africana, conforme demonstra parte do material cerâmico encontrado na área das senzalas de um dos engenhos da Chapada dos Guimarães [figura 03]. Podemos perceber que os fragmentos apresentam signos cruciformes, incisos em apliques circulares ou, em alguns casos, de forma impressa. Esses símbolos têm sido frequentemente associados pelos estudiosos ao cosmograma bakongo, cultura pertencente às sociedades do norte de Angola e do sul da República Popular do Congo, sendo que no Brasil tais elementos compuseram o repertório simbólico dos escravizados da nação Congo (SYMANSKI, 2013). Na Chapada, os registros mostram que indivíduos pertencentes a essa nação começaram a se destacar demograficamente entre os anos de 1830 e 1870 (SYMANSKI, 2013). Para os bakongo, o círculo preenchido por signos cruciformes representa o movimento do sol ao redor do planeta e a linha paralela marca a fronteira entre o mundo dos vivos e o mundo dos mortos (SYMANSKI, 2010). Dessa maneira, se revelam conhecimentos construídos por uma sociedade que não somente se dedicou a observar e a interpretar a dinâmica entre o planeta e os astros, como também apresentou uma teoria a respeito de seu funcionamento, a qual se encontra expressa por meio de signos na materialidade ressignificada além-oceano.

03

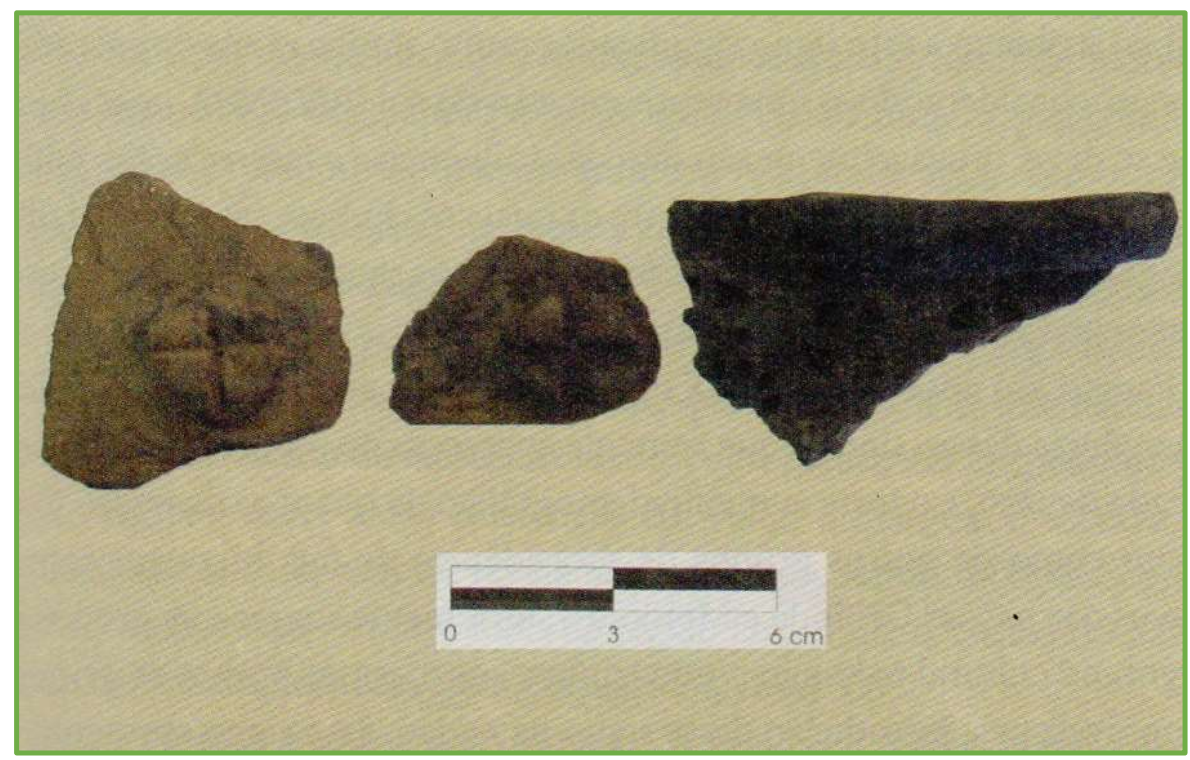

Fonte: SYMANSKI, 2013, p. 43.

\section{Considerações finais}

Logo na abertura do texto mencionamos que, dentre os quase mil estudantes do ensino básico goianiense convidados a representarem os exemplares da cultura material que acreditam estar associados às sociedades africanas e às comunidades afrobrasileiras, a maioria escolheu retratar berimbaus, tambores, colares e chicotes (ULHOA, 2018). Essa realidade pode ser explicada por diversos fatores, mas, por ora, 
Revista do Corpo Discente do Programa de Pós-Graduação em História da UnB

Em TEMPO DE HISTÓRIAS | Brasília-DF | n. 36 | p. 328-347 | jan./jun. 2020.

ISSN 2316-1191

importa ressaltarmos que os dados indicam sobretudo o desconhecimento relativo à complexidade do universo material dos africanos e de seus descendentes por parte dos estudantes. Nos parece especialmente revelador que considerem o chicote enquanto uma materialidade pertencente às comunidades afro-brasileiras, quando, na prática, foram ferramentas manipuladas pelos escravistas e por seus aliados no intuito de marcarem brutalmente os corpos negros. Portanto, nos parece importante ressaltar que o chicote integra, antes de mais nada, o repertório das elites brancas escravistas, muito embora os africanos e seus descendentes tenham sido colocados enquanto os alvos de sua bestialidade, expressa, em termos materiais, por aquele mesmo instrumento de tortura. Nesse sentido, compreendemos que análises da cultura material em sala tem o potencial de, no mínimo, permitir que os estudantes não se limitem à modelos reducionistas e estereotipados. Entretanto, para além disso, acreditamos que revelam epistemologias antieurocêntricas e anticolonialistas.

Mediante os exemplos apresentados, retirados de pesquisas empreendidas por arqueólogos dedicados ao estudo da cultura material da diáspora, percebemos que, no que concerne ao repertório dos africanos e de seus descendentes, o mesmo não se coloca enquanto mera prática material, mas, mais do que isso, se estabelece como uma soma de estratégias materiais possíveis (SOUZA, 2013). Nesse caso, abordar as materialidades em termos de estratégia significa compreender que, ao se constituírem e se expressarem materialmente segundo saberes, símbolos e sentidos próprios, a contrapelo, pois, das colonialidades do poder, do saber e do ser, tais sujeitos também revelam um poderoso repertório de resistência. Nesse sentido, consideramos que epistemologias são construídas associadas às estratégias materiais cotidianas dos africanos e de seus descendentes, pressupondo que as mesmas de algum modo comunicam uma parcela da “[...] dimensão cognitiva das lutas de resistência contra a opressão e contra o conhecimento que legitima essa mesma opressão" (SANTOS, 2019, p. 18). Portanto, a cultura material pode colaborar para que se construam práticas de ensino marcadas pela pluralidade epistemológica, nas quais os conhecimentos que permitem às materialidades existirem possam ser evidenciados em sua legitimidade.

\section{Referências}

ABUD, Kátia; SILVA, André; ALVES, Ronaldo. Ensino de História. São Paulo: Cengage, 2010.

BARROS, José d'Assunção. Fontes históricas: revisitando alguns aspectos primordiais para a pesquisa histórica. Mouseion. Canoas, n. 12, pp. 129-159, 2012.

BITTENCOURT, Circe. Ensino de História: fundamentos e métodos. São Paulo: Cortez, 2011.

CARVALHO, José Jorge de. Encontro de saberes e descolonização. In: BERNARDINOCOSTA, Joaze; MALDONADO-TORRES, Nelson; GROSFOGUEL, Ramón. Decolonialidade e pensamento afrodiaspórico. Belo Horizonte: Autêntica, 2019.

GOMES, Nilma. O movimento negro educador. Petrópolis: Vozes, 2017. 
ESPERANÇA Garcia. A cor da cultura, s/d. Disponível em: $<$ http://antigo.acordacultura.org.br /herois/heroi/ esperancagarcia> Acesso em: 20 de abril de 2020.

LIMA, Tânia; SENE, Glaucia; SOUZA, Marcos André de. Em busca do Cais do Valongo. Anais do Museu Paulista. São Paulo, n. 1, vol. 6, pp. 299-391, 2016.

LIMA, Tânia. Cultura material: a dimensão concreta das relações sociais. Revista Museu Emílio Goeldi. Belém, v. 6, n. 1, pp. 11-23, 2011.

MALDONADO-TORRES, Nelson. Sobre la colonialidade del ser. In: CASTRO-GOMÉZ, Santiago; GROSFOGUEL, Ramon (Orgs.). El giro decolonial: reflexiones para una diversidade epistêmica más allá del capitalismo global. Bogotá: Siglo del Hombre, 2007.

MARQUES, Lucas. A vida dupla das coisas. Textos Graduados. Brasília, v. 1, pp. 63-78, 2015.

MENESES, Ulpiano de. Cultura material no estudo das sociedades antigas. Revista de História. São Paulo, n. 115, pp. 103-117, 1983.

MIGNOLO, Walter. La opción de-colonial: desprendimiento y apertura. Tabula Rasa. Bogotá, n. 8, pp. 243-281, 2008.

Histórias locais/Projetos globais. Belo Horizonte: UFMG, 2003.

PAZ, Francisco. Na casa de Ajalá: comunidades negras, patrimônio e memória contracolonial no Cais do Valongo. Brasília, UnB, 2019. [Dissertação de Mestrado].

QUIJANO, Aníbal. Colonialidad del poder, cultura y conocimiento en América Latina. Ecuador Debate. Quito, n. 9, pp. 227-238, 1998.

SANTOS, Boaventura. O fim do império cognitivo: a afirmação das epistemologias do sul. Belo Horizonte: Autêntica, 2019.

SOUZA, Marcos André de. Por uma arqueologia da criatividade: estratégias e significações da cultura material utilizada pelos escravos no Brasil. In: AGOSTINI, Camilla (Org.). Objetos da escravidão. Rio de Janeiro: 7Letras, 2013.

A vida escrava portas adentro: uma incursão as senzalas o Engenho de São Joaquim, Goiás, século XIX. Revista Maracanan. Rio de Janeiro, n. 07, v. 07, pp. 83-109, 2011.

SYMANSKI, Luís Cláudio. A arqueologia da diáspora africana nos Estados Unidos e no Brasil: problemáticas e modelos. Afro-Ásia. Salvador, n. 49, pp. 159-198, 2014.

Africanos no Mato Grosso: cultura material, identidades e cosmologias. In: AGOSTINI, Camilla (Org.). Objetos da escravidão. Rio de Janeiro: 7Letras, 2013.

. Cerâmicas, identidades escravas e crioulização nos engenhos de Chapada dos Guimarães. Revista de História da Unisinos. São Leopoldo, n. 14, pp. 294-310, 2010.

ULHOA, Clarissa. A cultura material no ensino da história e da cultura afro-brasileira e africana: por uma pedagogia decolonial. Goiânia: UFG, 2018 [Tese de Doutorado]. 
Revista do Corpo Discente do Programa de Pós-Graduação em História da UnB

EM TEMPO DE HISTóRIAS | Brasília-DF | n. 36 | p. 328-347 | jan./jun. 2020.

ISSN 2316-1191

WEDDERBURN, Carlos. Novas bases para o ensino da história da África no Brasil. In: Educação Antirracista: caminhos abertos pela Lei Federal 10639/2003. Brasília: MEC, 2005, pp. 134-142.

WISSENBACH, Maria. Cartas, procurações, escapulários e patuás: os múltiplos significados da escrita entre escravos e forros na sociedade oitocentista brasileira. Revista Brasileira de História da Educação. Campinas, n. 4, pp. 103-122, 2002. 